\title{
Êxodo: A influência da cultura estrangeira na criação pictórica
}

José Tazza ${ }^{1}$

Resumo: E se Pablo Picasso (1881-1973) não tivesse viajado a Paris? O artigo inicia com esta pergunta com a intenção de descrever a experiência de conhecer outros lugares (culturas, países, realidades) e verificar como isso influenciou alguns artistas e suas criações, falando exclusivamente da pintura e usando como referente o artista plástico peruano Sérvulo Gutierrez (1914-61). Com uma narrativa em primeira pessoa desenvolve um tema que está presente no mundo da arte: a migração por motivos além dos econômicos ou políticos. Contando as experiências próprias do autor como estrangeiro na Academia curitibana, são apresentados argumentos para descrever esta experiência frequente no mundo da pintura tanto Moderna como Contemporânea.

Palavras-chave: Arte latino-americana; Artista estrangeiro; Pintura Moderna; Pintura Contemporânea.

Resumen: ¿Y si Pablo Picasso (1881-1973) no hubiese viajado a Paris? El artículo inicia con esta pregunta con la intención de describir la experiencia de conocer otros lugares (culturas, países, realidades) y verificar como eso influenció a algunos artistas en su creación, hablando exclusivamente de la pintura y usando como referencia al artista plástico Sérvulo Gutierrez (191461). Con la narrativa en primera persona se desenvuelve un tema que está presente en el mundo del arte: la migración por motivos más que políticos o económicos. Contando las experiencias propias como un extranjero en la Academia curitibana, se presentan argumentos para describir esta experiencia recurrente en el mundo de la pintura tanto Moderna como Contemporánea.

Palabras-clave: Arte Sudamericano; Artista extranjero; Pintura Moderna; Pintura Contemporánea.

${ }^{1}$ Graduando do Curso Superior de Pintura da Universidade Estadual do Paraná Unespar, Escola de Música e Belas Artes do Paraná - EMBAP, Campus I, Curitiba, Paraná, Brasil.

Revisão geral e coelaboração do texto: Prof. ${ }^{a}$ Dr. ${ }^{a}$ Katiucya Perigo, Universidade Estadual do Paraná - Unespar, Escola de Música e Belas Artes do Paraná - EMBAP, Campus I, Curitiba, Paraná, Brasil. 


\section{Introdução}

E se Pablo Picasso (1881-1973) não tivesse viajado a Paris, ou se Anita Malfatti (1889-1964) não tivesse ido a Nova York fariam as mesmas pinturas? A resposta é óbvia: Nunca saberemos. Nosso intuito é entender a influência dessas viagens na História da Arte latino-americana.

O conhecido Picasso foi um pintor, escultor e desenhista espanhol e reconhecidamente um dos maiores artistas do século XX. É considerado um dos artistas mais famosos e versáteis de todo o mundo, tendo criado milhares de trabalhos, não somente pinturas, mas também esculturas e cerâmicas, usando, enfim, todos os tipos de materiais. Depois de estudar arte em Madrid, Picasso fez sua primeira viagem a Paris em 1900, a então capital artística da Europa. Lá ele adquire experiências importantes e consegue alcançar notoriedade (ARGAN, 1992, p. 680-1).

A pintora brasileira Anita Malfatti, conhecida por sua polêmica exposição em 1917, foi uma figura importante para a renovação das artes plásticas no Brasil. Em 1915 a pintora partiu para Nova York, onde estudou pintura e teve a liberdade de pintar livremente, sem limitações estéticas. Foi a fase em que pintou seus quadros mais brilhantes. Anita Malfatti volta para São Paulo em 1917, e no dia 20 de dezembro realiza sua polêmica exposição, com 53 obras. O escritor Monteiro Lobato, crítico de arte do jornal $O$ Estado de São Paulo, publicou um artigo intitulado "Paranoia ou mistificação?", que era uma crítica à mostra expressionista de Anita Malfatti. Isto serviu de estopim para o movimento modernista no Brasil (ALMEIDA, 1976, p. 26). 
Conhecer outra realidade afetaria diretamente a expressão pictórica? Considerando que formamos nosso próprio conceito de mundo a partir do que vemos, sentimos e percebemos como realidade, é provável que sim.

Aqui cabe sublinhar que os artistas mencionados tiveram dois pontos em comum: Ambos saíram de seus países; Seus trabalhos foram reconhecidos na História da Arte.

Parto da afirmação de que no mundo da arte as migrações, que existem desde que o mundo é mundo, indiferente do motivo, ajudaram a desenvolver a arte e a representação pictórica com uma característica especial aqui no Sul da América em relação à Europa ou América do Norte. Tento então explicar os caminhos oblíquos por onde passam as influências, bem como busco compreender essa experiência especial dos artistas.

As influências que o artista tem no decorrer de sua vida são diversas, mas aqui escrevo sobre um denominador comum: o conhecimento de outra realidade cultural para o desenvolvimento da arte, partindo da suposição que essa percepção da realidade alheia está diretamente inserida na obra pictórica do artista. Até que ponto as influências estão refletidas na obra de pintores que mudam de endereço e como compreendê-las?

É importante também mencionar mais um pintor que teria sofrido influências em suas pinturas depois de conhecer outras culturas, Paul Gauguin (1848-1903). Gauguin nasceu em Paris em 1848. Entre 1851 e 1855, ele viveu no Peru. De volta à França, ingressou aos 17 anos 
na marinha mercante, serviu na frota de guerra durante os conflitos entre a França e a Alemanha (1870) e, finalmente, tornou-se um bem-sucedido corretor de valores. Casou-se em 1873 e teve cinco filhos. Gauguin pintava quadros no seu tempo livre, como um hobby. Entre 1876 e 1882, expôs obras no Salão de Paris e nas Exposições Impressionistas. Finalmente, em 1883, buscando inspiração na cultura "primitiva", Gauguin passa a residir no Taiti (CHIPP, 1999, p. 54-82).

Além dos já mencionados Pablo Picasso e Anita Malfatti, poderia ser feita uma grande pesquisa e o material seria abundante, mas acredito que o apropriado aqui é destacar essas "influências" neste lado do mundo: a América Latina.

Com uma narrativa em primeira pessoa desenvolvo a primeira parte deste artigo a partir da perspectiva de um peruano estudante em Curitiba, Paraná. Voltando no tempo - década de 1930-40 -, na segunda parte do texto falo do artista plástico peruano Sérvulo Gutierrez com o mesmo intuito, relatar e compreender como a influência de novos conhecimentos aparece presente na expressão artística.

\section{Um estrangeiro na Academia curitibana}

O momento tinha chegado, era hora de estudar artes numa escola oficial e deixar o empirismo e a prática da pintura compreendida até então. Foi numa noite de sábado, em que depois de passar o dia pintando e vendendo quadros nas ruas, compartilhei a decisão com um colega. Eu tinha 30 anos e há algum tempo viajava e financiava as viagens a outras cidades como "pintor de rua". Tinha viajado por quase oito anos e, em 
março de 2007, cruzei a fronteira chegando à cidade de Curitiba. Três anos depois resolvi ficar e estudar para fazer da arte uma profissão, foi um imperativo.

Tomei a decisão no ano de 2010 e festejava essa mudança em um boteco no centro da cidade, quando um colega começou a falar o que ele entendia sobre a prova que faziam na Escola de Belas Artes de Curitiba (EMBAP) ${ }^{2}$. Mencionou satirizando que no momento da apresentação do portfólio faziam sempre a pergunta: "O que você entende de arte?" e afirmou com rebeldia, que nós artistas, que trabalhávamos na rua "fazíamos arte que já não é arte". Eu não acreditei e nem dei importância ao comentário, porque não quis ter preconceitos sobre algo que tinha me proposto a conhecer. Decidi preparar-me e dediquei meu tempo a isso.

$\mathrm{Na}$ entrevista não fizeram aquela pergunta, as provas transcorreram bem e fui aceito na Escola de Belas Artes de Curitiba, depois de fazer os testes de seleção e apresentar os documentos obrigatórios, dentre eles o portfólio, que era composto por trabalhos bastante acadêmicos - retratos, figura humana e paisagens diversas -, bem como o visto de permanência.

\footnotetext{
${ }^{2}$ Escola de Música e Belas Artes do Paraná - EMBAP é um estabelecimento estadual de ensino superior fundado em 1948 e reconhecido pelo Conselho Federal de Educação desde 1954. O movimento em prol da criação da EMBAP surgiu em 1947 na Sociedade de Cultura Artística Brasílio Itiberê, tendo logo recebido apoio da Academia Paranaense de Letras, do Círculo de Estudos Bandeirantes, do Centro de Letras do Paraná, do Centro Feminino de Cultura, da Sociedade de Amigos de Alfredo Andersen, do Instituto de Educação e do Colégio Estadual do Paraná (EMBAP, [20--], não paginado).
} 
Lembro-me do dia que tomei essa decisão. Apesar de não dar importância ao comentário, meu colega deixou um rastro de interrogação na minha testa. Eu gostava de arte, pintava e desfrutava do prazer de praticar a pintura, mas qual era meu pensamento sobre a arte? Qual seria a perspectiva neste lado do continente a respeito da arte?

Eu tinha escutado muito sobre o assunto, mas não tinha feito essa pergunta frente ao espelho. Uma vez dentro da Escola percebi que os sinais de interrogação não eram de exclusividade do estrangeiro, vários dos meus companheiros procuravam entender entre outras coisas o que era a arte? Qual é o conceito de artista atualmente? O que é a pintura nos dias de hoje? E assim por diante.

$\mathrm{Eu}$ era um autodidata que pintava seguindo a Academia, conhecendo perspectivas e claro-escuros, misturando conceitos entre surrealismo e realismo, tinha pintado muros com aerografia e sprays, tinha aprendido tudo isso de maneira autodidata. Os novos conceitos da arte não tinham passado despercebidos, mas eram conceitos aleatórios e ordenados no caminho, conhecimento que abrangia abordagens sobre a pintura, e alguns dos seus momentos e representantes principalmente na América do Sul.

No entanto, foi necessário dentro da Academia ampliar o pensamento, reorganizar os conceitos que eu tinha adquirido até o momento. O que é arte nos dias de hoje? O que é ser um artista plástico? Algumas tentativas de respostas a essas perguntas são debatidas na Academia em Curitiba: A arte é um conceito, um sentimento, é multidisciplinar, arte é pintura que morre e volta à vida, a arte é bela para 
alguns e para outros espetacularmente feia, arte é ativismo, ou "artivismo", arte é mentira disfarçada de verdade ou verdade que chega numa mentira, arte é tudo e nada disso, arte é filosofia, história e exercício, arte era tudo e nada ao mesmo tempo.

$\mathrm{Na}$ Academia apareceram muitos conceitos "novos", e outros foram descobertos. Para ajudar a entender todas essas respostas que chegavam a partir dos professores, era imprescindível organizar a aparente confusão criada:

Sobretudo nas chamadas "artes plásticas", nos últimos anos tornou-se evidente um fosso entre o público e as obras apresentadas como artísticas. A rigor, a crise é ainda mais grave, pois muitos artistas que se consideram igualmente modernos, e o são, não reconhecem nas obras de muitos de seus contemporâneos qualquer validade estética. A isto se soma o fato de que não apenas entre os artistas que ocupam espaço na mesma contemporaneidade existe essa negação, mas muitos intelectuais também importantes dentro da chamada modernidade não reconhecem em muitas das obras hoje apresentadas em galerias e museus o caráter de inovação ou de criatividade artística. Por tanto, estamos diante de um fenômeno insólito e perturbador dentro das relações sócio-artísticas. [...] A sensação que se tem hoje é que muitos autores desses produtos não apenas estão repetindo essencialmente experiência que vão do Impressionismo ao Dadaísmo, mas sobretudo são despreparados técnica e intelectualmente para a tarefa a que se propõem [...] (SANT'ANNA, 2003, p. 16).

Quando falo de confusão falo, de alguma forma, dessa incerteza que em muitas ocasiões está presente dentro de lugares onde a informação é constante. Na medida em que se pratica a pintura e se desenvolve a 
pesquisa sobre a profissão, depois de um tempo dentro da Academia, a vontade de querer saber algo absoluto vai se modificando, e surge a vontade de conhecer a expansão do conceito da arte.

Em todo caso na Academia (se percebe com o tempo) que confusão não é mais que falta de informação, de alguma maneira esses novos pensamentos (inter-multidisciplinares) estão requerendo do artista, além de uma boa técnica, aprofundamento em pesquisa e conhecimento sobre a história, pensamento, e abordagens desta profissão. Compreendi, então, o que meu amigo estava querendo dizer na ocasião que afirmou que os artistas de rua fazem um tipo de arte que já não é arte. Às vezes, parece que simplesmente pintar já não é mais válido para que alguém seja um artista, poderia resumir desta maneira, mas para compreender melhor esses novos pontos de vista é necessário rever primeiro os pontos de partida.

\section{O primeiro professor de arte, a migração de Andrés Vargas}

Um dos primeiros contatos diretos com a pintura contemporânea aconteceu aproximadamente no ano de 2002, nessa época, eu estava no último ano do curso de Publicidade. Éramos um grupo de alunos do curso e estávamos prestigiando o artista plástico Andrés Vargas (Lima, 1963) na sua exposição individual chamada "Espace invader", algo assim como espaço invadido.

Andrés era professor da disciplina de Desenho. Na sala de aula só falava sobre o que precisaríamos como publicitários, nada de mais, 
nada que praticando não se alcance (storyboards, desenhos rápidos usando técnicas diversas e conhecimento elementar).

Ele convidou os alunos para a sua exposição, e estivemos presentes. Para a maioria foi como conhecer uma pessoa diferente daquele professor com o qual estávamos acostumados. Diante de nossos olhos não só se apresentavam pinturas resolvidas (óleo sobre tela, figura humana, sombras, etc.), mas também paisagens que se confundiam pela crueza e pela contrariedade, forma e figura trabalhadas com tinta a óleo falavam de enxergar de outro jeito a própria realidade.

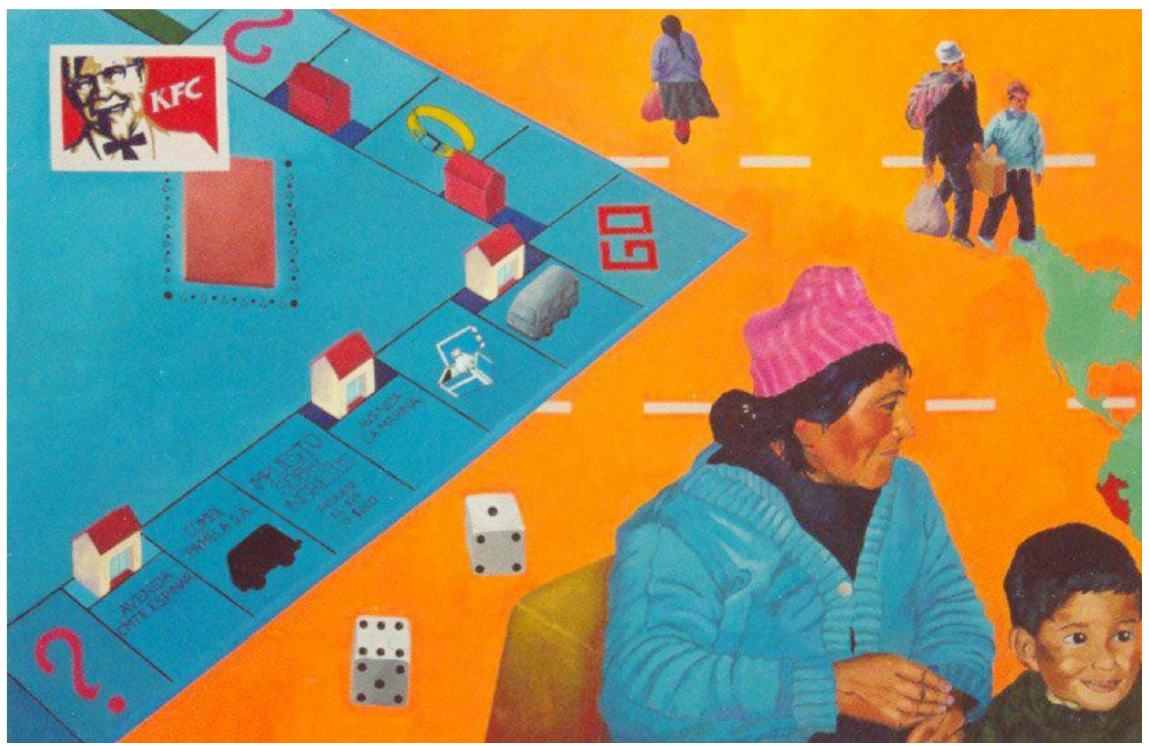

Figura 1 - VARGAS, André. Migración, 1999. 1 Óleo sobre tela, color., 1,20m x $1,70 \mathrm{~m}$

O quadro chamado "Migración" foi uma daquelas obras que chamaram minha atenção, estávamos ali aproximadamente em 15 alunos de Publicidade numa galeria num bairro central da cidade de Lima 
confusos diante de uma pintura que apresentava os personagens em meio a mapas e jogos de azar.

Naquele dia começava a entender que a pintura não ficava adormecida no deleite do espectador para escutar simplesmente dele "Que bonito" ou um elogio das técnicas, mas também poderia falar (e às vezes atingir, incomodar) diretamente ao observador sem esperar nenhuma palavra.

Lembrando aquele episódio e o analisando à luz dos conceitos adquiridos percebo que a arte havia começado a falar já faz muito tempo com outras disciplinas como a filosofia, a antropologia, e até a psicanálise. Era fabuloso saber dessa diversidade de linguagem, mas conforme os conceitos eram ampliados, se exigia também ampliar meu olhar binocular. Era preciso um novo olhar: trinocular, um terceiro olho.

Um dos pressupostos fundamentais da arte contemporânea diz que o público tem que aprender a ver de uma forma nova o novo. De fato cada momento artístico novo e cada autor relevante ensinam a ver e a reler o mundo. $\mathrm{O}$ artista autêntico cria seu público e ensina seu público a lê-lo [...]. É urgente desenvolver uma pedagogia do olhar. Desautomatizar a falsa modernidade. Uma pedagogia do olhar deve ensinar não apenas a ver e a rever, mas exercitar astuciosamente o que chamo de terceiro olhar (SANT'ANNA, 2003, p. 38).

Essa pedagogia do olhar foi entendida literalmente, como diria meu professor Andrés: "Se ve con los ojos y se observa con el cérebro" ("Se vê com os olhos e se observa com o cérebro" (tradução minha). Concordando com Affonso Romano de Sant'Anna, acredito que hoje em 
dia é necessário criar esse terceiro olhar e poder iniciar a carreira pintando se você é um pintor, mas seguir com um senso crítico mais comprometido.

Em seguida apresento duas imagens de dois trabalhos meus realizados em momentos diferentes. O primeiro é um quadro do ano de 2010 e o segundo um trabalho realizado em agosto de 2014, onde apresento o desprendimento da forma como exercício.

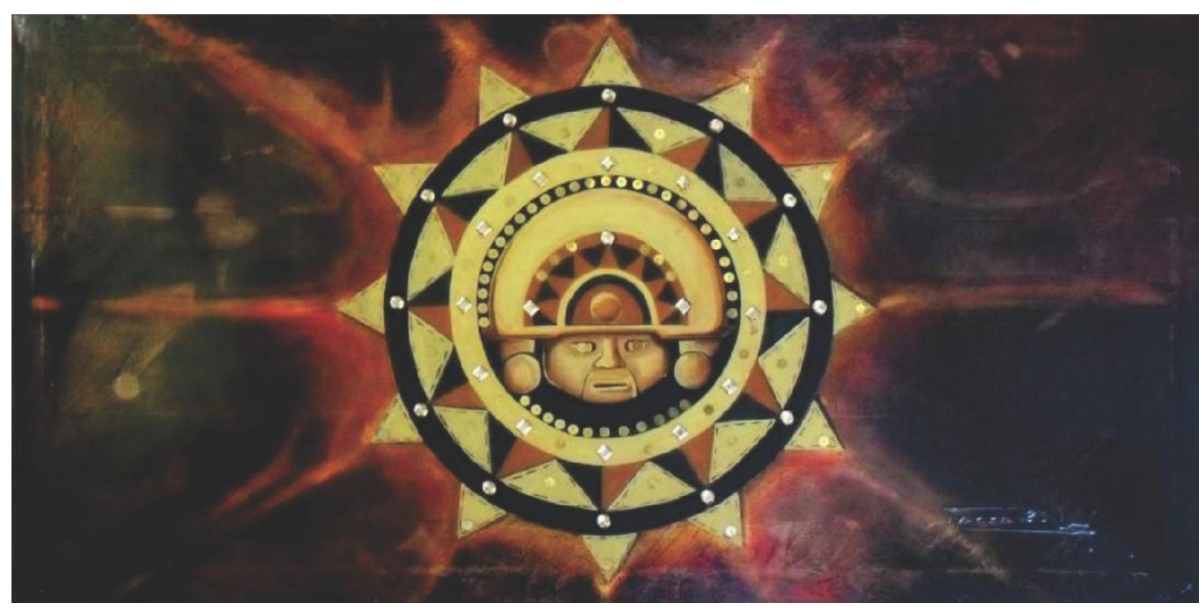

Figura 2 - TAZZA, José. Inti, 2010. 1 Acrílico sobre tela, color., 120 cm x 60 cm 


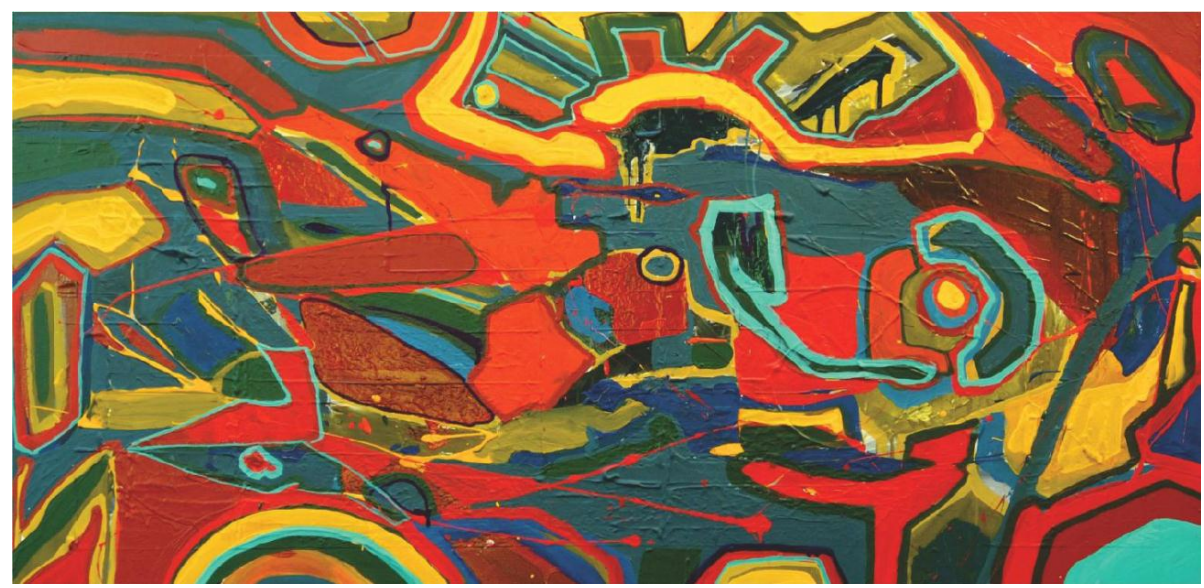

Figura 3 - TAZZA, José. Inti, 2014. 1 Acrílico sobre tela, color., 120 cm x 60 cm

Esses quadros pretendem apresentar a mudança do tratamento da pintura na minha obra, eles corporificam os novos conceitos (culturais/acadêmicos), que fizeram com que eu iniciasse um novo entendimento da pintura ao executá-la.

Vejo, então, a importância de conhecer a História da Arte quando se decide viver da pintura, para começar a entender os discursos, é importante apoiar-se em uma base cronológica dos acontecimentos artísticos. É como fazer um mapa que se pode utilizar para o entendimento dos temas que se abordam dentro e fora das salas de aula, a prática por outro lado é a Íris desse terceiro olho (que menciona Affonso Romano de Sant'Anna), que deveríamos exercitar ou nos acostumar.

A Escola vai desenvolvendo um novo conceito sobre o significado do que hoje se considera ser artista, ou ao que parece o que poderia fazer alguém se considerar um artista: não copiar simplesmente as imagens, mas observá-las. 
Contudo, não acredito na Academia - ou no estudo acadêmico como fundamentalmente necessária para desenvolver a pintura nos dias de hoje. Acredito que ela é uma influência, mas não necessariamente a única. Existem por outro lado pintores que "mudaram de endereço" por outros motivos e sem a Academia contribuíram para a arte de seus países.

\section{Um estrangeiro fora da Academia, Sérvulo Gutierrez Alarcón}

Pensando na minha experiência em terra estrangeira lembrei-me de um artista igualmente peruano cuja obra teria sido influenciada por experiências em outros países: Sérvulo Gutierrez. Antes de falar sobre este artista peruano que não visitou academias, é importante pensar que quando alguém menciona o período "Moderno" da História da Arte, geralmente o relaciona diretamente a Manet e aos ismos que apareceram a partir do final do século XI na Europa. Na maioria das explicações breves sobre o tema figura os seguintes três períodos: Renascimento, Moderno e Contemporâneo. Estas seriam as três fases que resumiriam os três últimos "momentos" da História da Arte.

Quanto ao Moderno se vê que existem controvérsias sobre os limites temporais e alguns de seus traços distintivos: como separar Clássico/Moderno, Moderno/Contemporâneo, Moderno/Pós-Moderno. Divergências à parte, se observa uma tendência em localizar na França do século XIX o início da Arte Moderna. A experiência urbana - ligada à multidão, ao anonimato, ao contingente e ao transitório - é enfatizada pelo poeta e crítico francês Charles Baudelaire (1821-67) como o núcleo da vida e da Arte Moderna. O Moderno não se define pelo tempo presente 
- nem toda a arte do período Moderno é moderna -, mas por uma nova atitude e consciência da modernidade, declara Baudelaire, em 1863, ao comentar a pintura de Constantin Guys (1802-92). A modernização de Paris - traduzida nas reformas urbanas implementadas por Haussmann, entre 1853 e 1870 - relaciona-se diretamente à sociedade burguesa que se define ao longo das revoluções de 1830 e 1848. A ascensão da burguesia traz consigo a indústria moderna, o mercado mundial e o livre comércio, impulsionados pela Revolução Industrial. A industrialização em curso e as novas tecnologias colocam em crise o artesanato, fazendo do artista um intelectual apartado da produção. "Com a industrialização, esse sistema entra em crise", afirma o historiador italiano Giulio Carlo Argan, "[...] e a arte moderna é a própria história dessa crise" (ENCICLOPÉDIA ITAÚ CULTURAL, Arte..., 2014, não paginado).

O termo Renascimento, ou Renascença, faz referência a um movimento intelectual e artístico surgido na Itália, entre os séculos XIV e XVI, e daí difundido por toda a Europa. À concepção medieval do mundo se contrapõe uma nova visão, empírica e científica, do homem e da natureza. A ideia de um 'Renascimento' nas artes e na cultura relaciona-se à revalorização do pensamento e da arte da Antiguidade Clássica e à formação de uma cultura humanista. A obra do pintor, arquiteto e teórico Giorgio Vasari (1511-74) constitui a principal fonte de informação acerca da Arte Renascentista italiana. A Arte Italiana como progresso, com seu ápice no século XV, fornece as balizas para os juízos críticos posteriores. A noção de Renascimento tal como entendida hoje é estabelecida pelo historiador suíço Jacob Burckhardt (1818-97) em seu 
livro A cultura do Renascimento na Itália (1867), que define o período como de grande florescimento do espírito humano, espécie de "descoberta do mundo e do homem" (ENCICLOPÉDIA ITAÚ CULTURAL, Renascimento..., 2014, não paginado).

Já a Arte Contemporânea é um conceito que tem duas acepções: ou se reporta à arte do período Moderno, ou seja, à arte desde o século XVIII, ou como é comumente aceito, se reporta à arte do Pós-Guerra, também denominada como segunda vanguarda do século XX. Numa definição mais atual, a arte do Pós-Guerra veio a encaminhar-se para um entendimento da prática artística que vai para lá da tradição das disciplinas históricas, definindo-se como uma disciplina ampla e com especificidades. Assim, a Arte Contemporânea tanto é tomada, em termos gerais, como a arte dos nossos dias, como é localizada no período que se segue à Segunda Guerra com uma afirmação nas décadas de 1960 e 1970. Neste sentido, a Arte Contemporânea daria lugar a uma arte PósHistórica, ou seja, a uma formulação artística que se radicaria no abandono das categorias, das narrativas e dos paradigmas que tinham formado a arte até o modernismo, para se assumir como uma prática social de contornos mais fluidos e mais próxima da Ciência e das disciplinas das Ciências Sociais e Humanas. Em qualquer um dos casos, a Arte Contemporânea está intimamente ligada ao surgimento das perspectivas conceptuais, bem como ao abandono das distinções tipológicas da História da Arte (SARDO, [20--], não paginado).

É certo que esses momentos se representam ou se expressam de diversas maneiras na Europa e aqui na América Latina. Acredito que se 
pode concordar quando se afirma que não existiu Renascimento latinoamericano ou se existiu não se expressou como o Renascimento italiano. Tanto no Brasil como no Peru a cronologia da arte tem apresentado histórias distintas de como entender ou assumir esses momentos que influenciaram o meio artístico.

No Brasil, por exemplo, foi com artistas como Cândido Portinari (1903-62), Tarsila do Amaral (1886-1973) e Anita Malfatti (1889-1964), bem como com a Semana de $22^{3}$ que a Arte Moderna foi consagrada.

Não quero expandir o tema, por isso falarei pontualmente do pintor peruano Sérvulo Gutierrez (1914-61) e suas influências na Argentina e em Paris.

No ano de 1922 enquanto aqui no Brasil se abria a famosa Semana, no Peru o artista completava ainda sete anos de vida, o país nesse ano estava sob o comando do ex-presidente Augusto B. Leguia ${ }^{4}$ e num panorama mundial se firmava um tratado delimitando fronteiras com a Colômbia.

\footnotetext{
${ }^{3}$ Nos dias 13, 15 e 17 de fevereiro de 1922 em São Paulo aconteceu o maior evento das artes no Brasil, a primeira Semana de Arte Moderna, no Teatro Municipal. Dias onde a pintura, escultura, poesia, literatura e música foram apreciadas e discutidas. Estavam presentes os artistas Di Cavalcanti, Anita Malfatti, Zina Aita, Vicente do Rego Monteiro, Ferrignac (Inácio da Costa Ferreira), Yan de Almeida Prado, John Graz, Alberto Martins Ribeiro e Oswaldo Goeldi entre outros (NETO, 2011, não paginado).

${ }^{4}$ Augusto B. Leguia nasceu em Lambayeque, Peru em 19 de fevereiro de 1863. Descendente da aristocracia espanhola, exitoso homem de negócios, funcionário de empresas estrangeiras, foi chamado a ser Ministro da Fazenda durante o governo de Manuel Candamo e José Pado, em momentos muito difíceis para o país. Como Ministro teve êxito levantando a economia nacional. Se tornou posteriormente Presidente entre 1908 a 1912 e entre 1919 a 1929: o chamado Oncenio de Leguia (MATOS, 2013, não paginado, tradução minha).
} 
Sérvulo Gutierrez foi um artista plástico autodidata que não visitou academias. Nasceu em 20 de fevereiro de 1914, ano que começa a Primeira Guerra Mundial. Ele nasceu em Ica, uma cidade que fica a 345 km da capital do Peru, Lima, e desde pequeno dedicou-se à restauração de obras de arte junto com sua família.

Aos nove anos perde a mãe e se muda para a capital do Peru, no centro da cidade de Lima, onde se instala na casa do seu irmão Alberto, no bairro do Rimac ${ }^{5}$ e trabalha com ele no seu atelier de restauração. Seu irmão mais velho o inicia na profissão de restauração, sua primeira escola.

No ano de 1929, instalado na cidade, ingressa no mundo do boxe amador, chegando a representar o país na categoria Galo na Argentina, na cidade de Córdoba no ano de 1935. Nessa viagem aproveita para visitar o amigo da família, o restaurador Pedro Velasco. O negócio de restauração continua em Lima com seus irmãos, depois ele viaja para Paris e inicia seu caminho como artista, como explica sua irmã Cely Gutierrez numa entrevista publicada em um jornal peruano:

No Peru foi campeão nacional de boxe na sua categoria e representou o país num campeonato sulamericano em Córdoba - Argentina. Depois do campeonato encontrou-se com dois amigos íntimos, mais velhos que ele. Um deles era o restaurador Pedro

\footnotetext{
${ }^{5} \mathrm{O}$ Rimac é um dos bairros mais antigos e populares de Lima, também é conhecido como o bairro de "Abajo del puente". No início de 1900 construiu-se a famosa "Ponte de pedra" sobre o rio Rimac. Este distrito cria-se politicamente em 2 de fevereiro de 1920, mediante Decreto Supremo promulgado durante o governo do Presidente Augusto B. Leguia. Antigamente foi uma zona habitada pelos indígenas que se dedicaram à pesca do camarão. Chegando os espanhóis, chamaram o lugar de "Bairro dos Í́ndios San Lazaro", onde mais tarde foram chegando brancos pobres, negros, mulatos.
} 
Velasco que levava antiguidades de Lima para Buenos Aires. Sérvulo morou com eles e trabalhou como restaurador de quadros e porcelana. Ali conheceu a cunhada do Pedro Velasco, Zulema Palomieri, com quem se casou, foi ali também que nasceu Lucy (sua única filha), mas o casamento durou pouco. Ele foi autorizado pela família da esposa a viajar aos Estados Unidos, mas por razões alheias ele ficou em Paris, sendo este o motivo de sua separação. Em Paris aprofundou sua carreira de artista. Não estudou em uma escola, foi autodidata, ali visitou museus, galerias de arte e conheceu pintores (GONZALES; PAREDES, 2014, não paginado, tradução minha).

O pintor peruano sofreu influência da arte desenvolvida na Europa e na Argentina, países que visita pela paixão pelo esporte e pintura. Em Paris, Sérvulo ao que parece conheceu o poeta Cesar Vallejo ${ }^{6}$. Essas viagens tiveram uma grande influência para o desenvolvimento de sua obra. Segue uma introdução da curadora Elida Román ${ }^{7}$ do artista que é exibida no documentário "Sérvulo"8:

Chegando a Europa conhece Juan Rios e Alejandro Sanchez Trujillo, Apurimac conhece Cesar Vallejo também, existe um desenho que é um retrato do poeta,

\footnotetext{
${ }^{6}$ César Vallejo nasceu em 1892, em Santiago de Chuco, região andina localizada ao norte do Peru, no seio de uma família com origens espanholas e indígenas. Desde pequeno conheceu a miséria, mas conheceu o afeto familiar. Longe de sua família, nunca escondeu que sofria de um incurável sentimento de orfandade. Estudou na Universidade de Trujillo, cidade onde descobriu a boemia, influenciado por jornalistas, escritores e políticos rebeldes. Em Trujillo, Vallejo publicou seus primeiros poemas antes de chegar a Lima no final de 1917. Nesta cidade lança seu primeiro livro: Los Heraldos Negros (impresso em 1918, lançado em 1919), um dos mais representativos exemplos de pósmodernismo (BANCO DA POESIA, 2010, não paginado).

${ }^{7}$ Curadora e Crítica de Arte, Lima, Peru.

8 Documentário "Sérvulo" (48 min 30). Disponível em: <https://www.youtube.com/watch?v=9PBPEzRmOeI>.
} 
Vallejo morre pouco depois. Se conheceram mas não tiveram uma grande relação por uma questão de tempo. Sérvulo viaja a Paris nos primeiros dias de 1938 e Vallejo morre pouco tempo depois, sua estadia em Paris se interrompe porque inicia a Segunda Guerra Mundial, e volta para a América Latina, mas não a Lima e sim a Buenos Aires.

Essas viagens teriam influenciado o seu trabalho. Para afirmar esta ideia apresento como exemplo três trabalhos do artista (Figuras 4, 5, 6). Nos dois primeiros pode-se observar o tema do retrato abordado de maneira diferente, como se fossem dois períodos diferentes (Figuras 4 e 5). O trabalho que leva o nome "Retrato de Mulher" (Figura 6) aborda também o tema do retrato, mas com mais ousadia. As figuras humanas, retratadas posteriormente à sua experiência no exterior, são mais despreocupadas, mais estilizadas, menos comprometidas com a figuração realista, com a fisionomia real do personagem. Certamente ele fora influenciado pelas vanguardas europeias. Serão então com estas últimas obras que ele trará a renovação para a arte peruana

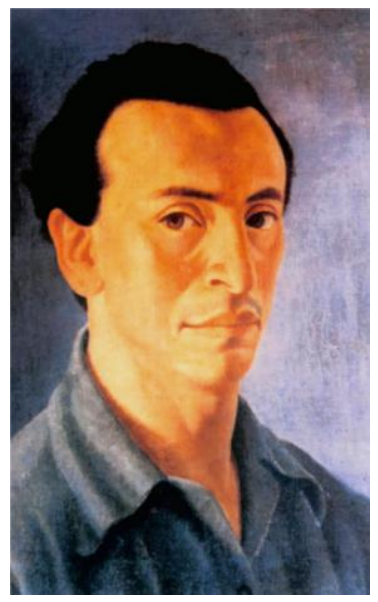

Figura 4 - GUTIERREZ, Sérvulo. Autorretrato, 1 óleo sobre tela, color. 


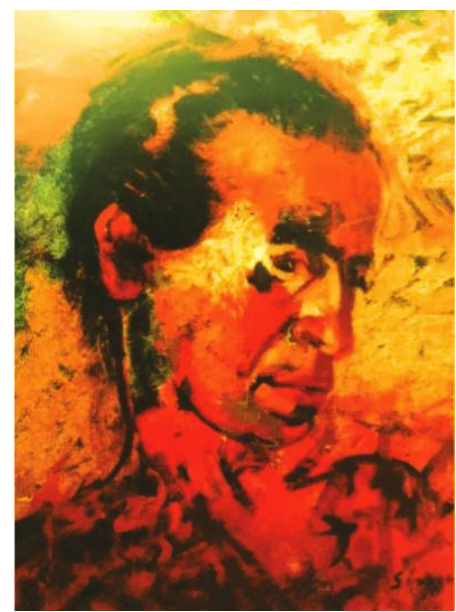

Na sua carreira como artista, ele vive pouco tempo fora do Peru (1935-40). Sempre trabalhando com cerâmica, escultura e pintura, se manteve trabalhando no meio artístico e cultural de Lima. Alguns dos seus trabalhos mais conhecidos são a pintura "Os Andes" e a escultura "As Amazonas" (Figura 7), que hoje se encontram no Museu Nacional de História Natural da Universidade de San Marcos, na cidade de Lima. Com esta obra ganhou o primeiro lugar no ano de 1942 na exposição que celebrava o quarto centenário do descobrimento do rio Amazonas.

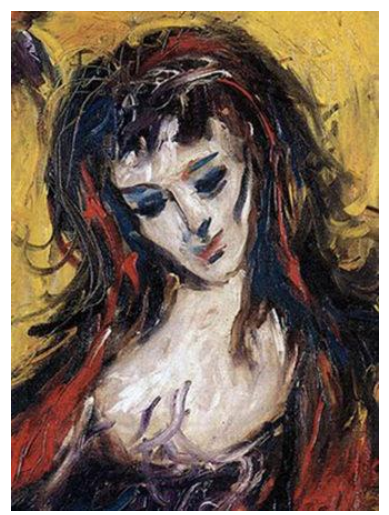

Figura 6 - GUTIERREZ, Sérvulo.

"Retrato de Mulher", 1 óleo sobre tela, color. 

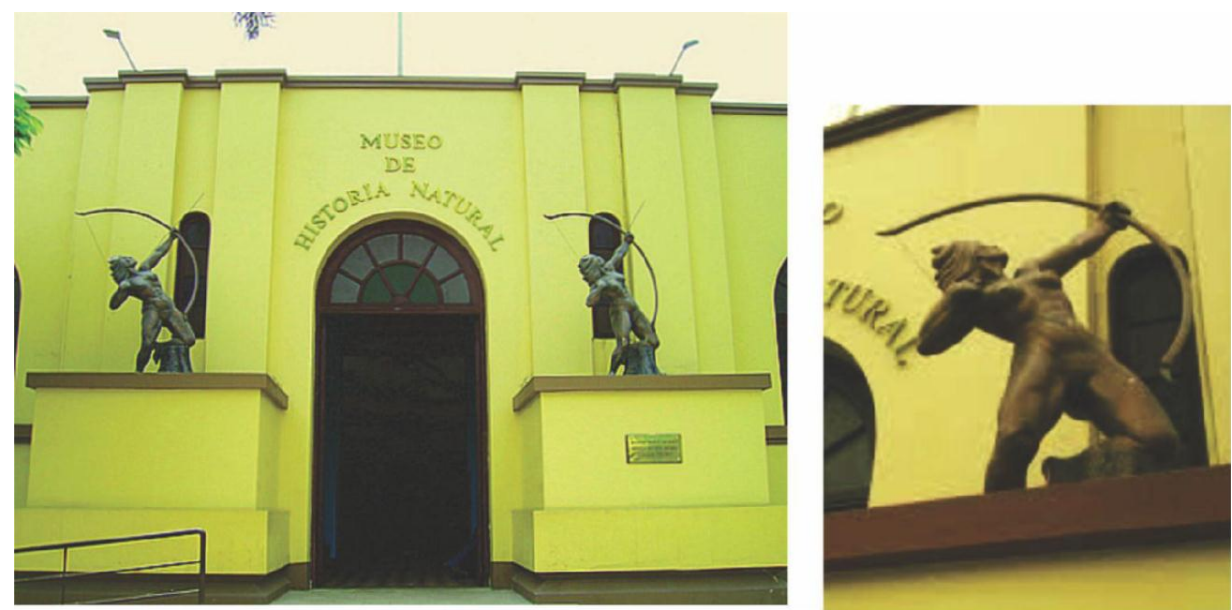

Figura 7 - GUTIERREZ, Sérvulo. As Amazonas, Museu Nacional de História Natural - Universidade de São Marcos, Lima, 1942.

Falece, em 1961, aos 47 anos por problemas de saúde. É considerado um dos mais importantes ou até mesmo o mais importante artista peruano. Este grande latino-americano se dedicou a ser artista e fez da arte o seu sustento, hoje tem trabalhos que figuram em lugares destacados.

\section{Conclusões}

As influências que ditaram o caminho da História da Arte muitas vezes podem ser fruto da vida acadêmica, mas também podem ser encontradas fora deste circuito. Em ambos os casos, que se referem aos dois pintores peruanos apresentados, sobressaiu à dedicação ao trabalho artístico. Tais colocações pretenderam demonstrar que conhecer outras culturas contribui para que o artista experimente a arte a partir de outras perspectivas culturais, sociais, históricas, etc. 
Esta primeira conclusão se vê reforçada nos relatos de Sérvulo Gutierrez e a na experiência própria do autor, que quando comparadas mostram um aprofundamento na pesquisa ou entendimento da arte da época tanto de maneira empírica como acadêmica, conceitual.

No entanto, é preciso tomar os cuidados necessários para comparar tanto o trabalho dos pintores viajantes como Pablo Picasso, Paul Gauguin, Sérvulo Gutierres ou Anita Malfatti, já que os conceitos da arte moderna, nesse sentido, estavam ainda sendo elaborados.

Acredita-se que tanto no Brasil, como no Peru ou na América do Sul, a cronologia da arte tem apresentado histórias distintas de como entender ou assumir esses momentos marcantes no meio artístico. A Semana de 22 teria sido um grande evento que promoveu a entrada da Arte Moderna no Brasil. Sérvulo Gutierrez, no Peru, teria também introduzido o Moderno a partir das pesquisas que faz e do contato informal, autodidata que teve com a arte europeia.

Conclui-se finalmente que no período Moderno, e poderíamos ampliar também para a atualidade, os conceitos de arte são compreendidos de maneira diferente na Europa e na América do Sul e que os que procuraram a imigração, ao final, contribuíram com a disseminação do conhecimento adquirido nos distintos lugares, culturas ou países. As imigrações, com o tempo, ajudam a compor uma possível genesis da Arte latino-americana, como hoje é entendida. 


\section{Referências}

ALMEIDA, Paulo Mendes de. De Anita ao Museu. São Paulo: Perspectiva, 1976.

ARGAN, Giulio Carlo. Arte Moderna. São Paulo: Companhia das Letras, 1992.

BANCO DA POESIA. Vida, Paixão e Morte de César Vallejo. Tradução de: Cleto de Assis. 2010. Disponível em: <http://cdeassis.wordpress.com/2010/03/19/vida-paixao-e-morte-decesar-vallejo/>. Acesso em: 14/09/2014.

CHIPP, Herschel Browning. Teorias da Arte Moderna. 2. ed. São Paulo: Martins Fontes, 1999.

DOCUMENTÁRIO. Sérvulo (48 min 30). Disponível em: <https://www.youtube.com/watch?v=9PBPEzRmOeI>. Acesso em: 14/09/2014.

EMBAP. Histórico. [20--]. Disponível em: $<$ http://www.embap.pr.gov.br/modules/conteudo/conteudo.php?conteud $\mathrm{o}=125>$. Acesso em: 02/11/2014.

ENCICLOPÉDIA ITAÚ CULTURAL. Verbete Arte Moderna. 2014. Disponível em: <http://enciclopedia.itaucultural.org.br/termo355/ArteModerna->. Acesso em: 02/11/2014.

Verbete Renascimento. 2014. Disponível em: <http://enciclopedia.itaucultural.org.br/termo3637/renascimento>. Acesso em: 02/11/2014.

GONZALES, Diana; PAREDES, Jorge. Sérvulo Gutiérrez: Una vida en el arte. El Comercio, El Dominical, Lima, Perú, 16 Febrero 2014. Disponível em: <http://elcomercio.pe/eldominical/actualidad/servulogutierrez-vida-arte-noticia-1709952 >. Acesso em: 14/09/2014. 
HIPERTEXTOS DEL ÁREA DE LA BIOLOGÍA. ADN mitocondrial y migraciones. [20--]. Disponível em: <http://www.biologia.edu.ar/evolucion/migra.htm>. Acesso em: $02 / 11 / 2014$.

MATOS, Jorge Moreno. Augusto B. Leguía (1863-1932). El Reportero de la Historia, 19 Febrero 2013. Disponível em: <http://www.reporterodelahistoria.com/2013/02/augusto-b-leguia-18631932.html\#.VEPmLCLF9Jc4>. Acesso em: 14/09/2014.

NETO, João Timotio. Semana de Arte Moderna de 22. Portal Arquitetônico, 4 Fevereiro 2011. Disponível em: $<$ http://portalarquitetonico.com.br/semanade22/>. Acesso em: $02 / 11 / 2014$.

SANT'ANNA, Affonso Romano De. Desconstruir Duchamp - Arte na hora da revisão. Rio de Janeiro: Viera\&Lent, 2003.

SARDO, Delfim. Dicionário Crítico de Arte, Imagem, Linguagem e Cultura. Verbete Arte Contemporânea. Fundação Côa Parque, [20--]. Disponível em: <http://www.artecoa.pt/index.php?Language $=$ pt $\&$ Page $=$ Saberes $\&$ SubPage $=$ Comunicaca oELinguagemArte $\&$ Menu2 $=$ OrigensDaArte $\&$ Filtro $=94 \&$ Slide $=94>$. Acesso em: 02/11/2014. 